\title{
Missed Opportunities for Depression Screening and Treatment in the United States
}

\author{
Elisabeth Kato, MD, MRP, Amanda E. Borsky, DrPH, MPP, Samuel H. Zuvekas, PhD, \\ Anita Soni, PhD, MBA, and Quyen Ngo-Metzger, MD, MPH
}

Purpose: This study estimates the prevalence of depression assessment in adults age 35 and older and how prevalence varies by sociodemographic characteristics and depressive symptoms.

Methods: We used a nationally representative survey, the Agency for Healthcare Research and Quality's Medical Expenditure Panel Survey, to evaluate if adults 35+ were being assessed for depression by their health care providers in 2014 and 2015. Using multivariate logistic regression, we examined the health and sociodemographic characteristics of patients associated with depression assessment.

Results: Approximately $50 \%$ of US adults aged $35+$ were being assessed for depression $(48.6 \% ; 95 \%$ CI, 45.5\%-51.6\%). The following were less likely to be assessed: men compared with women (OR, 0.58 ; 95\% CI, 0.46-0.72), adults 75+ compared with adults 50 to 64 years old (OR, 0.47; 95\% CI, 0.320.69), the uninsured compared with those with private insurance $(\mathrm{OR}, 0.30 ; 95 \% \mathrm{CI}, 0.18-0.51)$, and adults without recognized depressive symptoms compared with those with recognized symptoms (OR, 0.39; 95\% CI, 0.24-0.63). Compared with non-Hispanic whites, the following were less likely to be assessed: Asian (OR, 0.35; 95\% CI, 0.19-0.67), Hispanic (OR, 0.47; 95\% CI, 0.29-0.75), and African American (OR, 0.42; 95\% CI, 0.27-0.67).

Conclusions: Many Americans are not having their depression needs assessed. Certain populations are more likely to be missed, including men, people over 75 years old, minorities, and the uninsured. Additional efforts are needed to determine methods to increase screening recommended by the United States Preventive Services Task Force and to ensure that all Americans have their mental health needs met. (J Am Board Fam Med 2018;31:389-397.)

Keywords: Depression, Health Personnel, Health Services Research, Logistic Models, Medically Uninsured, Mental Health, Prevalence, Surveys and Questionnaires

Depression is one of the most common mental illnesses in America. In 2015, 6.7\% of adults aged 18 or older reported at least one major depressive

This article was externally peer reviewed.

Submitted 17 October 2017; revised 8 January 2018; accepted 10 January 2018.

From Agency for Healthcare Research and Quality, Rockville, $\mathrm{MD}$.

Funding: This paper was supported as part of the Agency for Healthcare Research and Quality intramural research program.

Conflict of interest: none declared.

Corresponding author: Amanda E. Borsky, DrPH, MPP, Agency for Healthcare Research and Quality, 5600 Fishers Lane, Mailstop 06E53A, Rockville, MD 20857 (E-mail: amanda.borsky@ahrq.hhs.gov).

Disclaimer: The findings and conclusions in this document are those of the author(s), who are responsible for its content, and do not necessarily represent the views of AHRQ. No statement in this report should be construed as an official position of AHRQ or of the U.S. Department of Health and Human Services. episode in the past year, and lifetime prevalence is considerably higher. ${ }^{1}$ Depression not only affects quality of life, but also is a leading cause of disability and is associated with higher mortality. ${ }^{2-4}$ Despite the prevalence and impact of this condition, a substantial proportion of people with depression in the United States are undiagnosed and untreated. ${ }^{5}$

In its 2009 and 2016 recommendations, the United States Preventive Services Task Force (USPSTF) recommended screening for major depressive disorders in the general adult population, regardless of whether they or their health care provider are aware that they have symptoms. ${ }^{6}$ However, little is currently known about the extent to which this recommendation of universal screen-

\footnotetext{
${ }^{1}$ The PSAQ was only administered to adults ages 35 and older.
} 
ing for depression is actually being implemented. The limited data available suggests that universal screening is not commonly practiced. One recent analysis of National Ambulatory Medical Care data from 2012 and 2013 found that screening for depression occurred in only $4.2 \%$ of visits (after excluding patients with a prior history of depression or with depressive symptoms as a chief complaint). ${ }^{7}$ A retrospective observational study of diabetic patients found that only $11 \%$ of patients with no history of depression (but who had depressive symptoms) were screened. ${ }^{8}$

Another question is the extent to which depression screening is being implemented equitably, that is, if some populations are more likely to receive screening than others. Adherence to clinical practice guidelines can be an important tool for reducing health inequities, while unequal implementation of preventive services can exacerbate existing disparities in health outcomes. Akincigil et $\mathrm{al}^{7}$ found that doctor visits that included African American patients were half as likely to conduct depression screenings compared with visits with patients who were white. In addition, the visits with elderly patients were less likely to include screening than visits with middle-aged patients. ${ }^{7}$ However, visits with patients who had multiple chronic conditions were more likely to include depression screening compared with other patients.

Without basic information about the prevalence of depression screening and who is being screened, it is not possible to determine whether we are making progress toward universal depression screening or where efforts to improve screening should be directed. Therefore, we analyzed data from the Medical Expenditure Panel Survey (MEPS) to answer the following questions: (1) who is getting screened and/or treated for depression?, (2) do screening/treatment rates vary by demographic characteristics, geographic location, or insurance status?, and (3) to what extent are people with and without depressive symptoms being screened and/or treated (ie, is the USPSTF recommendation being followed?).

\section{Methods}

\section{Study Design}

We used data from the Agency for Healthcare Research and Quality's (AHRQ) MEPS ${ }^{9}$ that were collected in the spring/fall of 2014 and spring of
2015. The MEPS is a nationally representative survey of the US civilian noninstitutionalized population that has been conducted annually since 1996 . The MEPS collects detailed data on health care services use and costs, health insurance coverage, health status and health conditions, and sociodemographic characteristics. The MEPS uses an overlapping panel design, with each household interviewed in 5 rounds, covering 2 full-calendar years.

This research was approved by the Chesapeake IRB, Secondary Analysis of Confidential Data from the Medical Expenditure Panel Survey (grant CRRI 0504015), June 5, 2017.

\section{Study Population and Sample}

The study population consisted of adults ages 35 and older residing in the community who completed both the Preventive Care Self-Administered Questionnaire $(\mathrm{PSAQ})^{1}(\mathrm{n}=2185$ completed PSAQ surveys) and the MEPS Self-Administered Questionnaire on behalf of themselves, resulting in a final study sample size of 1852 .

Using propensity-score reweighting methods, we adjusted the MEPS PSAQ sample weight for SAQ nonresponse and item nonresponse to the depressive symptoms scales on the MEPS SAQ and mood-screening question on the PSAQ.

\section{Study Measures}

Primary Outcome

Our primary outcome was the percentage of respondents who had been assessed for depression, which we defined as whether a respondent reported screening for depression and/or receiving mental health treatment. Those who reported already receiving treatment for depression or other mental health issues were presumed to have been assessed previously (whether through screening or via case finding).

We defined depression screening based on a positive response to the following question in the PSAQ: "In the past 12 months, has your doctor, nurse, or other health care professional asked you about your mood, such as whether you are anxious or depressed? You may have answered in person, on article, or on a computer."

We defined any mental health treatment during 2014 according to published algorithms using MEPS data ${ }^{10-12}$ based on a self-report of having a mental health-related outpatient visit or hospital 
stay or the use of psychotropic medications. A mental health-related visit was defined based on whether the main reason for the visit was for mental health treatment or counseling to a specialty mental health provider or had a mental health condition associated with the visit. Psychotropic medications included antidepressants, antipsychotics, and antianxiety medications if taken for a mental health condition, anticonvulsants if taken for a mental health condition, substance use medications, and all stimulants.

\section{Depressive Symptoms}

We stratified the main outcome by presence or absence of depressive symptoms based on a score of $\geq 3$ on the 2-item Patient Health Questionnaire (PHQ-2) $)^{13,14}$, which is a validated measure of depressive symptoms and an accepted clinical screening tool for depression. ${ }^{6}$ The PHQ-2 asks how often a person has been bothered over the past 2 weeks by problems of "feeling down, depressed, or hopeless" and "little interest or pleasure in doing things." Responses ranged from "not at all" (0) to "nearly every day" (3). Previous research has established construct and criterion validity of the PHQ-2 with a suggested score $\geq 3$ indicating having depressive symptoms that warrant the need for further evaluation. ${ }^{13,14}$

\section{Sociodemographic Characteristics}

We included the following sociodemographic characteristics: age (35 to 49,50 to 64,65 to 74 , and $75+$ ), sex, race/ethnicity (Hispanic, Non-Hispanic White or Other, non-Hispanic Black, non-Hispanic Asian), education (less than high school diploma, high school diploma, some college, bachelor's degree, master's degree or higher), poverty status $(100 \%$ to $124 \%$ of federal poverty level [FPL] [near poor], $125 \%$ to $199 \%$ of FPL [low income], $200 \%$ to $399 \%$ of FPL [middle income], $400 \%$ of FPL [high income]), census region (Northeast, Midwest, South, West), metropolitan statistical area, insurance coverage (any private, public only, or uninsured), and number of chronic conditions. We also included the responses to the standard one-item perceived health status scale (excellent, very good, good, fair or poor).

\section{Statistical Analysis}

We estimated the percent assessed for depression (screened and/or treated) by depressive symptoms
(Patient Health Questionnaire [PHQ2] $\geq 3$ or not), and by other sociodemographic characteristics described above. We also estimated a multivariable logistic regression of the odds of being screened and/or treated by PHQ2 status and the same sociodemographic characteristics.

All analyses were conducted in the Stata/MP 14.1 software. All estimates and statistics reported account for the stratified and clustered design of the MEPS by using the adjusted MEPS PSAQ weight.

\section{Results}

During 2014-2015, approximately 50\% of US adults aged $35+$ were assessed for depression (48.6\%; 95\% CI, 45.5\%-51.6\%), either through screening or as part of treatment for depression. The following sociodemographic characteristics were associated with a lower likelihood of assessment for depression: males; youngest (35 to 49) and oldest $(75+)$ adults; Asian, non-Hispanic; Hispanic; Black, non-Hispanic; and those who were less educated, had higher perceived health status, and were uninsured (see Table 1).

After controlling for demographic factors in a multivariable model, we found that results were similar (see Table 3). Males had lower odds of screening and/or treatment for depression compared with women (OR, 0.58; 95\% CI, 0.46-0.72). Adults 75 and older had lower odds of assessment for depression compared with adults 50 to 64 years old (OR, 0.47; 95\% CI, 0.32-0.69). When we examined disparities by race/ethnicity and compared white, non-Hispanic adults to other races/ethnicities, the following had lower odds of assessment for depression: Asian, non-Hispanic (OR, 0.35; 95\% CI, 0.19-0.67); Hispanic (OR, 0.47; 95\% CI, 0.29-0.75); and Black, non-Hispanic (OR, 0.42; $95 \%$ CI, 0.27-0.67). Lower education status was also associated with lower odds of assessment for depression. Adults with less than a high school diploma (OR, 0.59; 95\% CI, 0.36-0.95) and adults with a high school diploma (OR, 0.52; 95\% CI, 0.35-0.75) had lower odds of assessment compared with adults with a master's degree or higher. There was no difference in depression assessment for adults with a bachelor's degree compared with those with a master's degree. There was no statistically significant relation between poverty status, region, or metropolitan statistical area with odds of assessment for depression. 
Table 1. Percent of Civilian Noninstitutionalized Population Assessed for Depression by Selected

Sociodemographic Characteristics, 2014/2015 $(\mathrm{n}=1852)$

\begin{tabular}{|c|c|c|c|c|}
\hline & $\begin{array}{l}\text { Unweighted } \\
\text { (N) }\end{array}$ & $\begin{array}{c}\text { Weighted } \\
\text { proportion (\%) }\end{array}$ & $\begin{array}{c}\text { Weighted percent } \\
\text { (95\% confidence intervals) }\end{array}$ & $P$ value \\
\hline Overall & 1852 & 100.0 & $48.6(45.5-51.6)$ & \\
\hline Sex & & & & $<.001$ \\
\hline Male & 841 & 47.4 & $42.5(38.5-46.5)$ & \\
\hline Female & 1011 & 52.6 & $54.0(50.1-58.0)$ & \\
\hline Age (years) & & & & $<.001$ \\
\hline 35 to 49 & 312 & 35.0 & $40.2(34.3-46.0)$ & \\
\hline 50 to 64 & 604 & 36.7 & $52.9(48.5-57.3)$ & \\
\hline 65 to 74 & 631 & 16.1 & $57.5(52.7-62.4)$ & \\
\hline $75+$ & 305 & 12.1 & $47.9(41.7-54.0)$ & \\
\hline Race/Ethnicity & & & & $<.001$ \\
\hline Hispanic & 199 & 12.4 & $31.3(23.6-39.0)$ & \\
\hline Non-Hispanic White/Other & 1368 & 72.6 & $54.4(51.1-57.7)$ & \\
\hline Non-Hispanic Black & 199 & 10.3 & $38.1(28.7-47.4)$ & \\
\hline Non-Hispanic Asian & 86 & 4.7 & $27.7(16.4-38.9)$ & \\
\hline Education & & & & .021 \\
\hline Less than high school diploma & 250 & 13.0 & $42.2(34.7-49.8)$ & \\
\hline High school diploma & 510 & 27.3 & $44.2(39.0-49.4)$ & \\
\hline Some college & 535 & 29.2 & $49.2(44.5-53.9)$ & \\
\hline Bachelor's degree & 307 & 17.4 & $55.8(49.4-62.2)$ & \\
\hline Master's degree + & 250 & 13.1 & $52.8(45.3-60.3)$ & \\
\hline Poverty status & & & & .182 \\
\hline$<100 \%$ of FPL (poor) & 224 & 13.0 & $55.3(46.7-63.8)$ & \\
\hline $100 \%$ to $124 \%$ of FPL (near poor) & 93 & 4.5 & $40.1(27.6-52.6)$ & \\
\hline $125 \%$ to $199 \%$ of FPL (low income) & 257 & 14.1 & $42.4(34.8-50.1)$ & \\
\hline $200 \%$ to $399 \%$ of FPL (middle income) & 521 & 29.1 & $48.2(43.0-53.4)$ & \\
\hline$>400 \%$ of FPL (high income) & 757 & 39.3 & $49.8(45.5-54.1)$ & \\
\hline Region & & & & .012 \\
\hline Northeast & 310 & 18.2 & $54.6(47.8-61.4)$ & \\
\hline Midwest & 421 & 21.6 & $51.8(45.2-58.4)$ & \\
\hline South & 702 & 38.0 & $47.0(41.8-52.2)$ & \\
\hline West & 419 & 22.2 & $43.2(36.9-49.5)$ & \\
\hline Metropolitan statistical area status & & & & .840 \\
\hline Non-metropolitan statistical area & 321 & 15.6 & $47.7(39.1-56.4)$ & \\
\hline Metropolitan statistical area & 1531 & 84.4 & $48.7(45.5-51.9)$ & \\
\hline Perceived health & & & & $<.001$ \\
\hline Excellent & 380 & 20.1 & $36.0(30.5-41.6)$ & \\
\hline Very good & 600 & 33.6 & $46.2(41.2-51.2)$ & \\
\hline Good & 578 & 30.9 & $50.7(45.4-56.0)$ & \\
\hline Fair/Poor & 294 & 15.4 & $65.8(59.4-72.1)$ & \\
\hline Insurance coverage $^{\dagger}$ & & & & $<.001$ \\
\hline Any Private & 1187 & 67.7 & $49.8(46.3-53.4)$ & \\
\hline Public only & 546 & 22.0 & $56.8(51.3-62.2)$ & \\
\hline Uninsured & 119 & 10.2 & $22.5(14.1-30.8)$ & \\
\hline
\end{tabular}

Source: Medical Expenditure Panel Survey, 2014 to 2015 . $^{9}$

${ }^{\dagger}$ The definitions for the insurance variables are the following: any private (person had any private insurance coverage, including TRICARE/CHAMPVA, any time during 2014), public only (person had only public insurance coverage during 2014), and uninsured (person was uninsured during all of 2014).

FPL, federal poverty level. 
Table 2. Civilian Non-Institutionalized Population Depression Assessment Rates by Depressive Symptom Status, 2014/2015 $(\mathrm{n}=1852)$

\begin{tabular}{|c|c|c|c|}
\hline & PHQ2 $\geq 3(\mathrm{n}=132)^{*}$ & PHQ2 $<3(\mathrm{n}=1720)^{*}$ & Difference \\
\hline & $\begin{array}{c}\text { Weighted percent } \\
\text { (95\% confidence intervals) }\end{array}$ & $\begin{array}{l}\text { Weighted percent } \\
\text { (95\% confidence intervals) }\end{array}$ & $P$ value \\
\hline$\%$ of population & $7.4(6.1 \%-8.9 \%)$ & $92.6(91.1-93.9)$ & \\
\hline$\%$ screened & $66.4(56.6-76.2 \%)$ & $40.4(37.5-43.2)$ & $<.001$ \\
\hline$\%$ any mental health treatment & $65.5(55.8-75.2 \%)$ & $19.4(17.0-21.8)$ & $<.001$ \\
\hline$\%$ screened and/or treated & $76.5(67.9-85.1 \%)$ & $46.3(43.2-49.5)$ & $<.001$ \\
\hline
\end{tabular}

Source: Medical Expenditure Panel Survey, 2014 to 2015 . $^{9}$

*The PHQ2 is the two-item Patient Health Questionnaire (PHQ-2), which is a validated measure of depressive symptoms and accepted clinical screening tool for depression. ${ }^{7,13,14}$

Adults with a better perceived health status were less likely to be assessed for depression. For example, adults with excellent perceived health status were less likely to be assessed than adults with fair/poor perceived health status (OR, 0.37; 95\% CI, 0.23-0.58). Adults with more chronic conditions were more likely to be assessed for depression (OR, 1.27; 95\% CI, $1.17-1.38)$. The uninsured were less likely to be assessed for depression compared with those with any private insurance coverage (OR, 0.30; 95\% CI, $0.18-$ 0.51). There was no significant difference between adults with public insurance compared with any private health insurance.

People without depressive symptoms (46.3\%; $95 \%$ CI, $43.2 \%-49.5 \%$ ) were less likely to be assessed than those with depressive symptoms (76.5\%; 95\% CI, $67.9 \%-85.1 \%)$ based on the PHQ2 (Table 2). After controlling for sociodemographic characteristics in a multivariable model, adults without recognized depressive symptoms were still less likely to be assessed than those with recognized symptoms (OR, 0.39; 95\% CI, 0.240.63 ) (see Table 3 ). In addition, nearly 1 in 4 people with depressive symptoms (PHQ2 $\geq 3$ ) are not assessed for depression; 76.5\% (95\% CI, 67.9\%$85.1 \%$ ) of people with PHQ2 $\geq 3$ are screened or treated for depression (Table 2).

\section{Discussion}

\section{Key Findings}

In this study, we focused on all US adults ages 35 and older to find out who is being assessed for depression-whether it be through screening or treatment for depression - and more importantly, who is not. Results show that approximately only half (48.6\%) of adults are being assessed for depression, whether through screening or as part of treatment for depression. These results demonstrate that universal screening for depression is not occurring in practice, despite the recommendations of the USPSTF. This is consistent with prior research., ${ }^{7,8}$

We found that people who score lower on measures of depressive symptoms $(<3$ on the PHQ2) have nearly 60 percent lower odds of being assessed (i.e. screened and/or treated) than people with higher PHQ scores ( $\geq 3$ ) scores. While this result is influenced by the inclusion of patients being treated for depression in the assessment group, it confirms that we are far from universal screening (i.e. screening regardless of signs and symptoms) and that some screening may, in fact, be case finding (i.e. targeted questions prompted by signs or patient concerns). Since prior research ${ }^{5,15}$ has demonstrated that clinical case finding misses as many as half of the patients with depression, this raises the concern that a significant portion of adults, especially those without obvious depressive symptoms, are not having their mental health needs assessed.

Prior research has demonstrated that the prevalence of depression is higher for some sociodemographic groups than others, such as women, young and middle-aged adults, nonwhite individuals, and those who had lower education and were poorer. ${ }^{16-18}$ It also has suggested that disparities exist in the assessment of depression. ${ }^{7,19}$ Our results show that men, adults age $75+$, minorities (Hispanic, Black, and Asian), adults receiving a high school diploma or less, and those who are uninsured are less likely to have been assessed for depression. In addition, adults who have excellent to good perceived health status, do not have de- 
Table 3. Civilian Noninstitutionalized Population Multivariable Logistic Regression of Health and Sociodemographic Characteristics Associated with Depression Assessment in the United States, 2014/2015

$(\mathrm{n}=\mathbf{1 8 5 2})$

\begin{tabular}{|c|c|c|}
\hline & $\begin{array}{l}\text { Odds ratio } \\
\text { (95\% confidence interval) }\end{array}$ & $P$ value \\
\hline \multicolumn{3}{|l|}{ Sex } \\
\hline $\begin{array}{l}\text { Male } \\
\text { Female (reference) }\end{array}$ & $0.58(0.46-0.72)$ & $<.001$ \\
\hline \multicolumn{3}{|l|}{ Age (years) } \\
\hline $\begin{array}{l}35 \text { to } 49 \\
50 \text { to } 64 \text { (reference) }\end{array}$ & $0.81(0.60-1.09)$ & .156 \\
\hline 65 to 74 & $0.83(0.62-1.10)$ & .200 \\
\hline $75+$ & $0.47(0.32-0.69)$ & $<.001$ \\
\hline \multicolumn{3}{|l|}{ Race/Ethnicity } \\
\hline \multicolumn{3}{|l|}{ Non-Hispanic White/other (reference) } \\
\hline Non-Hispanic Black & $0.42(0.27-0.67)$ & $<.001$ \\
\hline Non-Hispanic Asian & $0.35(0.19-0.67)$ & .002 \\
\hline \multicolumn{3}{|l|}{ Education } \\
\hline Less than high school diploma & $0.59(0.36-0.95)$ & .032 \\
\hline High school diploma & $0.52(0.35-0.75)$ & .001 \\
\hline Some college & $0.72(0.49-1.07)$ & .101 \\
\hline Bachelor's degree & $1.13(0.76-1.68)$ & .539 \\
\hline Master's degree+ (reference) & & \\
\hline \multicolumn{3}{|l|}{ Poverty status } \\
\hline$<100 \%$ of FPL (poor) & $1.42(0.93-2.19)$ & .108 \\
\hline $100 \%$ to $124 \%$ of FPL (near poor) & $0.79(0.42-1.51)$ & .475 \\
\hline $125 \%$ to $199 \%$ of FPL (low income) & $0.92(0.58-1.44)$ & .703 \\
\hline $200 \%$ to $399 \%$ of FPL (middle income) & $1.11(0.84-1.47)$ & .450 \\
\hline$>400 \%$ of FPL (high income) (reference) & & \\
\hline \multicolumn{3}{|l|}{ Region } \\
\hline \multicolumn{3}{|l|}{ Northeast (reference) } \\
\hline Midwest & $0.90(0.61-1.34)$ & .609 \\
\hline South & $0.87(0.62-1.23)$ & .432 \\
\hline West & $0.76(0.51-1.12)$ & .165 \\
\hline \multicolumn{3}{|l|}{ MSA Status } \\
\hline Non-metropolitan statistical area & $0.82(0.56-1.21)$ & .316 \\
\hline \multicolumn{3}{|l|}{ Metropolitan statistical area (reference) } \\
\hline \multicolumn{3}{|l|}{ Perceived health } \\
\hline Excellent & $0.37(0.23-0.58)$ & $<.001$ \\
\hline Very good & $0.51(0.33-0.78)$ & .002 \\
\hline Good & $0.62(0.43-0.91)$ & .015 \\
\hline \multicolumn{3}{|l|}{ Fair/poor (reference) } \\
\hline \multicolumn{3}{|l|}{ Insurance coverage } \\
\hline \multicolumn{3}{|l|}{ Any private (reference) } \\
\hline Public only & $1.20(0.86-1.68)$ & .276 \\
\hline Uninsured & $0.30(0.18-0.51)$ & $<.001$ \\
\hline \multicolumn{3}{|l|}{ PHQ2 $\geq 3$} \\
\hline No & $0.39(0.24-0.63)$ & $<.001$ \\
\hline \multicolumn{3}{|l|}{ Yes (reference) } \\
\hline No. of chronic conditions & $1.27(1.17-1.38)$ & $<.001$ \\
\hline Constant & $8.25(4.23-16.07)$ & $<.001$ \\
\hline
\end{tabular}

Source: Medical Expenditure Panel Survey, 2014 to 2015. ${ }^{9}$

FPL, federal poverty level; MSA, Metropolitan Statistical Area; PHQ2, Patient Health Questionnaire. 
pressive symptoms (PHQ2 <3), and have fewer chronic conditions are also less likely to have been assessed for depression. Prior research has shown that nearly 60 percent of office visits are with patients with one or more chronic conditions. ${ }^{20}$ This suggests that, contrary to concerns that depression will be overlooked in patients with multiple comorbidities, it is patients without chronic health issues, and who are less likely to go to the doctor, that do not have the opportunity to be assessed.

Our results did not find a statistically significant association between several sociodemographic factors and depression assessment (eg, poverty status, region, and metropolitan statistical area). This could be due to potential confounders, such as insurance status or education. Future research with a larger sample size is needed to confirm this study's findings and more closely examine the sociodemographic characteristics that are (and are not) associated with depression assessment.

Our results show that much remains to be done to achieve universal screening for depression. The USPSTF recommends screening for depression in the general adult population, including pregnant and postpartum women and cautions that screening should be implemented with adequate systems in place to ensure accurate diagnosis, effective treatment, and appropriate follow-up. Screening for depression can improve outcomes, particularly when screening is coupled with system changes that help ensure adequate treatment and follow-up. ${ }^{21,22}$ If practices face resource limitations, the fact that minorities, the elderly, and those with less education and access to health care are both more likely to suffer from depression and less likely to be assessed suggests that these populations should perhaps be prioritized for screening. Prior research has shown that it is effective to screen and treat-low income and minority patients in primary care settings. ${ }^{23}$ However, given that we know that this screening is still not universally implemented, more research is needed on how to overcome the barriers to adequate depression screening and treatment. ${ }^{6}$ This is especially true for primary care practices that serve poorer communities and are most likely to struggle with competing needs.

Clinical practices may also want to think about how to ensure screening for patients who have less contact with the health care system due to better physical health. Results from the PSAQ show that $36 \%$ of people not assessed for depression did not see their doctor within the past 12 months. The use of care managers, as part of collaborative care models, is one way to help achieve more frequent contacts with patients than the typical clinician visits. ${ }^{24,25}$

Other promising strategies that may help clinicians and health care delivery systems improve depression assessment include the use of electronic medical reminders and panel management support to improve the uptake of preventive services. ${ }^{26}$ Another study in a family practice clinic showed that use of a decision algorithm improved compliance with the identification of patients with depression. ${ }^{27}$ The decision algorithm described the process that nurses should use for screening and following-up screening results. There are also available resources to help guide integration of behavioral health in primary care and other ambulatory settings. ${ }^{28}$

\section{Limitations}

There are 4 main limitations to this study. First, when survey respondents said they had been asked about depressive symptoms, the survey structure did not allow us to identify whether they had been asked as part of a true screening, or if they had been asked as part of management of a previously diagnosed depression. Therefore, we combined those who reported having been asked about depression and those who were being treated for depression into a new category "assessed for depression." Although this precludes an analysis of the relationship between screening and treatment, it allowed us to also more clearly identify who has not been assessed at all. Second, given that MEPS is based on self-reporting, there is always the potential for recall bias. Third, because the survey is based on self-reporting, household respondents may underreport the number and types of mental health conditions they experienced, due to the stigma surrounding mental health. ${ }^{29}$ Fourth, the survey question about screening is broadly phrased and probably overestimates the rate of formal depression assessment.

\section{Conclusions}

Despite national recommendations that all adults be screened for depression, many Americans are not having their depression needs assessed. Certain populations are more likely to be missed, including men, people over 75, minorities, and the uninsured. Additional efforts are needed to determine how to effectively achieve universal screening for depres- 
sion and ensure that all Americans have their mental health needs met.

We appreciate the efforts of David Meyers and Therese Miller, Agency for Healthcare Research and Quality; Russ Mardon, PhD, Westat; Shannon Fair, RN, MPH, Westat; Phuong Hoang, PhD, formerly of Westat; Mary Masters, MS, MSPH, formerly of Westat; Wilson Pace, MD, University of Colorado; and Brandon Combs, MD, University of Colorado, for helping to develop the PSAQ.

To see this article online, please go to: http://jabfm.org/content/ 31/3/389.full.

\section{References}

1. Center for Behavioral Health Statistics and Quality. Key substance use and mental health indicators in the United States: Results from the 2015 National Survey on Drug Use and Health (HHS Publication No.SMA 16-4984, NSDUH Series H-51). 2016. Retrieved from http://www.samhsa.gov/data/.

2. Whooley MA, Browner WS. Association between depressive symptoms and mortality in older women. Study of Osteoporotic Fractures Research Group. Arch Intern Med 1998;158:2129-35.

3. Stromberg R, Backlund LG, Johansson SE, Lofvander M. Mortality in depressed and non-depressed primary care Swedish patients: A 12-year follow-up cohort study. Fam Pract 2013;30:514-9.

4. Chang HJ, Lin HC, Lee HC, Lin CC, Pfeiffer S. Risk of mortality among depressed younger patients: A five-year follow-up study. J Affect Disord 2009; 113:255-62.

5. Olfson M, Blanco C, Marcus SC. Treatment of adult depression in the United States. JAMA Intern Med 2016;176:1482-91.

6. Siu AL, Bibbins-Domingo K, Grossman DC, et al. Screening for depression in adults: US Preventive Services Task Force recommendation statement. JAMA 2016;315:380-7.

7. Akincigil A, Matthews EB. National rates and patterns of depression screening in primary care: Results from 2012 and 2013. Psychiatr Serv 2017:68: 660-666.

8. Barnacle M, Strand MA, Werremeyer A, Maack B, Petry N. Depression screening in diabetes care to improve outcomes: Are we meeting the challenge? Diabetes Educ 2016;42:646-51.

9. Agency for Healthcare Research and Quality. Medical Expenditure Panel Survey. Available from: https://meps.ahrq.gov/mepsweb/.

10. Garfield RL, Zuvekas SH, Lave JR, Donohue JM. The impact of national health care reform on adults with severe mental disorders. Am J Psychiatry 2011; 168:486-94.

11. Meyerhoefer CD, Zuvekas SH. New estimates of the demand for physical and mental health treatment. Health Econ 2010;19:297-315.
12. Zuvekas SH, Fleishman JA. Self-rated mental health and racial/ethnic disparities in mental health service use. Med Care 2008;46:915-23.

13. Kroenke K, Spitzer RL, Williams JB. The Patient Health Questionnaire-2: Validity of a two-item depression screener. Med Care 2003;41:1284-92.

14. Lowe B, Kroenke K, Grafe K. Detecting and monitoring depression with a two-item questionnaire (PHQ-2). J Psychosom Res 2005;58:163-71.

15. Mitchell AJ, Vaze A, Rao S. Clinical diagnosis of depression in primary care: A meta-analysis. Lancet 2009;374:609-19.

16. Kessler RC, Berglund P, Demler O, et al. The epidemiology of major depressive disorder: Results from the National Comorbidity Survey Replication (NCS-R). JAMA 2003;289:3095-105.

17. Substance Abuse and Mental Health Services Administration, Results from the 2013 National Survey on Drug Use and Health: Mental Health Findings, NSDUH Series H-49, HHS Publication No. (SMA) 14-4887. Rockville, MD: Substance Abuse and Mental Health Services Administration, 2014.

18. Ko JY, Farr SL, Dietz PM, et al. Depression and treatment among U.S. pregnant and nonpregnant women of reproductive age, 2005-2009. J Womens Health (Larchmt) 2012;21:830-6. Available from: doi: 10.1089/jwh.2011.3466.

19. Cardemil EV, Nelson T, Keefe K. Racial and ethnic disparities in depression treatment. Curr Opin Psychol 2015;4:37-42.

20. National Ambulatory Medical Care Survey: 2014 state and national summary tables. Centers for Disease Control and Prevention, National Center for Health Statistics 2014.

21. Pignone M, Gaynes BN, Rushton JL, et al. Screening for depression. In: U.S. Preventive Services Task Force Evidence Syntheses, formerly Systematic Evidence Reviews. Rockville, MD: Agency for Healthcare Research and Quality; 2002.

22. O'Connor E, Rossom RC, Henninger M, et al. Screening for Depression in Adults: An Updated Systematic Evidence Review for the U.S. Preventive Services Task Force. Evidence Synthesis No. 128. AHRQ Publication No. 14-05208-EF-1. Rockville, MD: Agency for Healthcare Research and Quality; 2016.

23. Meyers MA, Groh CJ, Binienda J. Depression screening and treatment in uninsured urban patients. J Am Board Fam Med 2014;27:520-9.

24. Institute for Clinical Systems Improvement. The DIAMOND Program: Treatment for Patients with depression in primary care. Bloomington, $\mathrm{MN}$ : Institute for Clinical Systems Improvement. 2014.

25. Shippee ND, Shah ND, Angstman KB, et al. Impact of collaborative care for depression on clinical, functional, and work outcomes: A practice-based evaluation. J Ambul Care Manage 2013;36:13-23. 
26. Loo TS, Davis RB, Lipsitz LA, et al. Electronic medical record reminders and panel management to improve primary care of elderly patients. Arch Intern Med 2011;171:1552-8.

27. Yackel EE, McKennan MS, Fox-Deise A. A nursefacilitated depression screening program in an Army primary care clinic: An evidence-based project. Nurs Res 2010;59:S58-65.
28. Korsen NBA, Peek CJ, Kathol R, et al. Integration Playbook. Agency for Healthcare Research and Quality; 2016.

29. Clement S, Schauman O, Graham T, et al. What is the impact of mental health-related stigma on help-seeking? A systematic review of quantitative and qualitative studies. Psychol Med 2015;45: $11-27$. 